\title{
Sistemas para Crescimento e Terminação de Bovinos de Corte a Pasto: Avaliação do Desempenho Animal e Características da Forragem ${ }^{1}$
}

\section{Ivanor Nunes do Prado², Fernanda Barros Moreira ${ }^{3}$, Ulysses Cecato², Fábio Yoshimi Wada ${ }^{4}$, Elir de Oliveira ${ }^{5}$, Fabíola Cristine de Almeida Rego 6}

\begin{abstract}
RESUMO - O objetivo deste trabalho foi avaliar o ganho em peso de novilhos em crescimento e terminação, o ganho de peso vivo por hectare e a qualidade da forragem em diferentes sistemas de produção a pasto, no inverno e verão. No inverno, foram avaliados sistemas de produção em pastagem de aveia preta (PAV) ou em grama estrela roxa (GER). No verão, foram avaliados sistemas de produção em pastagem de milheto (MIL), capim-Mombaça (MOM) ou grama estrela roxa (GER) e o efeito do sistema de produção utilizado no inverno sobre o desempenho animal no verão. No inverno, o sistema PAV propiciou maiores peso final (PF $381 \mathrm{~kg}$ ), ganho médio diário (GMD $0,64 \mathrm{~kg} / \mathrm{dia}$ ) e ganho de peso vivo/ha (GPV/ha $233 \mathrm{~kg}$ ), quando comparado ao sistema GER (PF $332 \mathrm{~kg}$, GMD $-0,01 \mathrm{~kg} / \mathrm{dia}$ e GPV/ha $-1,38 \mathrm{~kg}$ ). Os animais mantidos no sistema PAV no inverno apresentaram menor desempenho no verão. Para os animais em crescimento, o sistema PAV no inverno e MIL no verão resultou em maior peso vivo final (447 kg) em relação aos sistemas PAV no inverno e MOM no verão (414 kg) e GER no inverno e MOM no verão (397 kg). Para os animais em terminação, não houve diferença no peso vivo final, no rendimento de carcaça e no peso de carcaça quente entre os sistemas avaliados. No inverno, a PAV e a GER apresentaram média de 15 e $5 \%$ de proteína bruta (PB), 51 e $81 \%$ de fibra em detergente neutro (FDN), 31 e $51 \%$ de fibra em detergente ácido (FDA) e 81 e $45 \%$ de digestibilidade in vitro da matéria seca (DIVMS). No verão, a GER, o MOM e MIL apresentaram média de 9,9 e $18 \%$ de PB, 65,64 e $54 \%$ de FDN, 40, 39 e $32 \%$ de FDA e 55,60 e $80 \%$ de DIVMS.
\end{abstract}

Palavras-chave: aveia preta, Cynodon, ganho de peso, Mombaça, sistema de produção

\section{Production Systems for Growing and Finishing Beef Steers in Pasture: Evaluation of Animal Performance and Forage Characteristics}

\begin{abstract}
The aim of this work was to evaluate the weight gain of growing and finishing steers, the life weight gain per hectare, and the forage quality in different grass production systems in the winter and summer. In the winter, the black oat pasture (BOP) and star grass (SGA) production systems were evaluated. In the summer, the millet (MIL), Mombaça (MOM), and star grass (SGA) production systems were evaluated and the effect of the production systems used in the winter on the animal performance in the summer was evaluated too. In the winter, the BOP system resulted in higher final body weigh (FW $381 \mathrm{~kg}$ ) higher average daily gain (ADG 0,64 kg/day) and higher life weight gain/ha (LWG/ha $233 \mathrm{~kg}$ ) when compared with SGA system (FW $332 \mathrm{~kg}$, ADG -0,01 kg/day and LWG/ha -1,38 kg). The animals kept on BOP system in the winter had lower performance in the summer. For the growing animals, the BOP in the winter and MIL in the summer resulted in higher final body weigh $(447 \mathrm{~kg})$ when compared with BOP in the winter and MOM in the summer (414 kg) and SGA in the winter and MOM in the summer $(397 \mathrm{~kg})$. For the finishing steers, there was no difference between the systems evaluated. In the winter, the BOP and SGA presented means levels of 15 and 5\% of crude protein (CP), 51 and 81\% of neutral detergent fiber (NDF), 31 and $51 \%$ of acid detergent fiber (ADF), and 81 and $45 \%$ of in vitro dry matter digestibility (IVDMD). In the summer, the SGA, MOM and MIL presented means levels of 9,9 , and $18 \%$ of CP, 65,64 , and $54 \%$ of NDF, 40, 39, and $32 \%$ of ADF, and 55, 60, and 80\% of IVDMD.
\end{abstract}

Key Words: black oat, Cynodon, Mombaça, production system, weight gain

\section{Introdução}

A pecuária de corte nacional caracteriza-se pela produção quase que exclusiva em sistemas baseados em pastagens. Nestes sistemas, pode-se dividir a produção de carne em dois períodos: o período de primavera/verão, quando a alta produção forrageira resulta em elevado desempenho animal, e, o período de outono/inverno, quando a produção limitada de pastagens retarda o crescimento animal ou provoca,

\footnotetext{
${ }^{1}$ Parte da Tese de Doutorado da segunda autora, Universidade Estadual de Maringá, UEM, Maringá, PR.

2 Professor do Departamento de Zootecnia da Universidade Estadual de Maringá, Av. Colombo, 5790, Maringá,PR, pesquisador do CNPq. E.mail: inprado@uem.br

${ }^{3}$ Bolsista PRODOC, Capes, Universidade Estadual de Londrina, Departamento de Zootecnia, Campus Universitário, Londrina, PR. E.mail: fbmoreira@sercomtel.com.br

${ }^{4}$ Mestrando em Produção Animal pela Universidade Estadual de Maringá.

5 Pesquisador do Instituto Agronômico do Paraná, IAPAR, PR. E.mail: eepiapar@iapar.br

${ }^{6}$ Doutoranda em Produção Animal pela Universidade Estadual de Maringá.
} 
até mesmo, perdas de peso durante este período.

Várias alternativas têm sido desenvolvidas para o período de baixa produção forrageira, como a suplementação em pastagens (Nussio et al., 2001), uso estratégico do confinamento (Bürgi, 2001) ou o uso de pastagens anuais de inverno (Canto et al., 1997). Assim, perdas ocorridas no período de baixa produção forrageira poderiam ser minimizadas e a eficiência de produção animal ampliada.

Por outro lado, a capacidade do animal em expressar maior taxa de crescimento após um período de restrição alimentar (Vilares, 1995), ou seja, o ganho compensatório não deve ser desconsiderado, uma vez que o maior ganho obtido durante o período de baixa produção forrageira pode ser diluído durante o período de maior produção forrageira.

Por isso, quando da avaliação do sistema de produção de bovinos de corte, é de fundamental importância o estudo e a interligação de todas as fases de produção, uma vez que o manejo adotado em determinada fase produtiva resultará em diferentes respostas na fase produtiva posterior (Drouillard \& Kuhl, 1999).

Durante o período de alta produção forrageira, muitas vezes o desempenho animal não é maximizado em função do baixo valor nutritivo das forrageiras tropicais. Uma alternativa para maior desempenho animal durante o período de alta produção forrageira seria a pastagem de milheto. Em função de sua qualidade nutricional, com teores de proteína bruta de até $14 \%$ e digestibilidade in vitro da matéria seca de até 70\% (Muehlmann et al., 1997), poderia resultar em maior desempenho animal, e, conseqüentemente, peso de abate em idades mais jovens.

O objetivo deste trabalho foi avaliar diferentes sistemas de produção animal no período de baixa e alta produção forrageira, assim como avaliar o efeito residual do manejo adotado no período de baixa produção forrageira sobre o desempenho de bovinos de corte, em crescimento e terminação, em diferentes sistemas de produção no período de alta produção forrageira.

\section{Material e Métodos}

O experimento foi conduzido na Fazenda Ibicatu, localizada no município de Centenário do Sul, região norte do Paraná. O solo da região é do tipo Latossolo vermelho escuro, textura média e o clima é caracterizado por subtropical úmido mesotérmico, conforme descrito pela SEAB (1994).
O experimento foi dividido em dois períodos experimentais: período de baixa produção forrageira, entre julho e novembro de 2000 e o período de alta produção forrageira, entre novembro de 2000 e março de 2001.

Período de baixa produção forrageira

Foram utilizados 40 novilhos, sendo 20 com peso inicial médio de $288 \mathrm{~kg}$ e 20 com peso inicial médio de $380 \mathrm{~kg}$. Os animais mais jovens eram $1 / 2$ Nelore $\mathrm{x} 1 / 2$ Girolando e os animais mais pesados, eram 12 da raça Nelore e $81 / 2$ Nelore $x 1 / 2$ Girolando. Os animais foram distribuídos de forma homogênea nos dois tratamentos: 1. Grama estrela roxa (GER); 2. Grama estrela roxa com acesso a pastagem de aveia preta por 4 horas diárias (PAV). Os animais foram pesados no início do experimento e a cada 28 dias, no período entre julho e novembro de 2000.

Foram utilizados dois piquetes de grama estrela roxa (Cynodon plectostachyus Pilger.) com área total de 30 ha, e um piquete de 4 ha com a pastagem de aveia preta cv IAPAR 61. Os animais permaneceram nestes piquetes no período de 07/07/2000 a 18/09/2000. Após este período, quando não havia mais possibilidade de pastejo na aveia preta, os animais dos dois tratamentos foram mantidos em um piquete de grama estrela roxa de 20 ha, onde permaneceram até $08 / 11 / 2000$.

O manejo adotado foi de pastejo contínuo, com carga fixa. A carga animal utilizada foi estipulada em função da disponibilidade de forragem e da taxa de crescimento da forragem estimada no início do período experimental, sendo estabelecida para que a disponibilidade de forragem durante o período experimental não fosse inferior a $2000 \mathrm{~kg} / \mathrm{ha}$. Os animais do tratamento PAV permaneciam em piquete de grama estrela roxa em área contígua ao piquete de aveia preta e, diariamente, no período entre 8 e $12 \mathrm{~h}$, eram deslocados para o piquete de aveia preta.

A semeadura da aveia preta foi realizada em $19 / 04 / 2000$. No plantio foram utilizados $200 \mathrm{~kg} / \mathrm{ha}$ do fertilizante 10:20:20. A adubação de cobertura foi realizada em 17/07/2000 com $75 \mathrm{~kg} /$ ha de uréia. A análise de solo do piquete de aveia preta apresentou a seguinte composição química: $\mathrm{pH}\left(\mathrm{H}_{2} \mathrm{O}\right)=6,2$; $\mathrm{Al}^{+3^{*}}=0,00^{*} ; \mathrm{H}^{+}+\mathrm{Al}^{+}=2,54^{*} ; \mathrm{Ca}^{+2}+\mathrm{Mg}^{+2}=2,76^{*}$; $\mathrm{Ca}^{+2}=1,91^{*} ; \mathrm{K}^{+}=0,11^{*} ; \mathrm{P}=2 \mathrm{ppm} ; \mathrm{C}=5,59 \mathrm{~g} / \mathrm{dm}^{3}$ $\left(* \mathrm{cmol} / \mathrm{dm}^{3}\right)$.

A disponibilidade da aveia preta foi determinada a cada 14 dias, quando foram coletadas 10 amostras de $0,25 \mathrm{~m}^{2}$ do piquete conforme técnica descrita por 
Houlderbaun \& Sollenberg (1992). Estas amostras foram secas em estufa a $55^{\circ} \mathrm{C}$ por 72 horas e moídas em moinho tipo faca com peneira de $1 \mathrm{~mm}$ de crivo, para análises posteriores.

Para avaliar a taxa de acúmulo de matéria seca, usou-se a técnica de Klingman et al. (1943). Foram utilizadas quatro gaiolas de exclusão de pastejo no piquete. A equação proposta por Campbell (1966) foi usada para calcular a taxa de acúmulo de matéria seca. Período de alta produção forrageira

Foram utilizados 35 novilhos, sendo 15 com peso inicial médio de $304 \mathrm{~kg}$ e $20 \mathrm{com}$ peso inicial médio de $397 \mathrm{~kg}$. Os animais mais jovens eram $1 / 2$ Nelore x 1/2 Girolando e os animais mais pesados, eram: 12 da raça Nelore e 8 1/2 Nelore x $1 / 2$ Girolando. Os animais foram distribuídos de forma homogênea nos diferentes tratamentos.

Para os animais em crescimento foram avaliados os seguintes sistemas de produção: GER + MOM (grama estrela roxa no inverno e capim-Mombaça no verão); PAV + MOM (pastagem de aveia preta no inverno e capim-Mombaça no verão) e PAV + MIL (pastagem de aveia preta no inverno e pastagem de milheto no verão).

Para os animais em terminação foram avaliados os seguintes sistemas de produção: GER + GER (grama estrela roxa no inverno e verão); GER + MIL (grama estrela roxa no inverno e pastagem de milheto no verão); PAV + MOM (pastagem de aveia preta no inverno e capim-Mombaça no verão) e PAV + MIL (pastagem de aveia preta no inverno e pastagem de milheto no verão).

Os animais foram pesados no início do experimento e a cada 28 dias, totalizando quatro períodos de 28 dias para os animais em crescimento e dois períodos de 28 dias para os animais em terminação. Para os animais em terminação foram avaliados apenas dois períodos, uma vez que estes animais foram abatidos em janeiro de 2001.

Foram utilizados três piquetes com área total de 31 ha, sendo um piquete de 19 ha de pastagem de milheto (Pennisetum americanum), um piquete de 8 ha de capim-Mombaça (Panicum maximum Jacq. $\mathrm{Cv}$. Mombaça) e um piquete de 4 ha de grama estrela roxa (Cyonodon plectostachyrus Pilger.). O manejo adotado foi de pastejo contínuo com carga variável. Foram utilizados animais reguladores "put-and-take" conforme descrito por Mott \& Lucas (1952) para controlar a lotação animal nas pastagens. $\mathrm{O}$ ajuste da carga animal foi realizado para manter a disponibili- dade de matéria seca total da forragem semelhante nos três piquetes.

O milheto foi semeado em 18/09/2000, com $25 \mathrm{~kg}$ de sementes/ha. No plantio foi utilizado $330 \mathrm{~kg}$ de superfosfato simples e a cobertura com nitrogênio foi realizada em 30/11/2000 com $50 \mathrm{~kg}$ de $\mathrm{N} / \mathrm{ha}$ na forma de uréia. A adubação foi realizada em função da análise de solo, que apresentou a seguinte composição química: pH $\left(\mathrm{H}_{2} \mathrm{O}\right)=6,4 ; \quad \mathrm{Al}^{+3 *}=0,00^{*}$; $\mathrm{H}^{+}+\mathrm{Al}^{+}=3,69^{*} ; \mathrm{Ca}^{+2}+\mathrm{Mg}^{+2}=6,98^{*} ; \mathrm{Ca}^{+2}=5,4^{*}$; $\mathrm{K}^{+}=0,59^{*} ; \mathrm{P}=2,95 \mathrm{ppm} ; \mathrm{C}=33,98 \mathrm{~g} / \mathrm{dm}^{3}\left(* \mathrm{cmol} / \mathrm{dm}^{3}\right)$.

Os piquetes de grama estrela roxa e mombaça já estavam estabelecidos e, 40 dias antes do experimento, estes foram roçados e adubados com $370 \mathrm{~kg}$ de super fosfato simples e $100 \mathrm{~kg} /$ ha da formulação N:P:K na proporção de 36:00:12. A análise de solo dos dois piquetes apresentaram composição química semelhante, onde a média foi de: $\mathrm{pH}\left(\mathrm{H}_{2} \mathrm{O}\right)=6,3$; $\mathrm{Al}^{+3^{*}}=0,00^{*} ; \mathrm{H}^{+}+\mathrm{Al}^{+}=2,25^{*} ; \mathrm{Ca}^{+2}+\mathrm{Mg}^{+2}=3,01^{*}$; $\mathrm{Ca}^{+2}=1,76^{*} ; \mathrm{K}^{+}=0,14^{*} ; \mathrm{P}=2 \mathrm{ppm} ; \mathrm{C}=2,01 \mathrm{~g} / \mathrm{dm}^{3}$ $\left(* \mathrm{cmol} / \mathrm{dm}^{3}\right)$.

Em ambos os períodos experimentais, a determinação da disponibilidade da forragem foi realizada a cada 28 dias, utilizando o método da dupla amostragem (Wilm et al., 1944), usando a equação proposta por Gardner (1986). Foram coletadas 5 amostras de 0,25 $\mathrm{m}^{2}$ a cada 28 dias, conforme técnica descrita por Houlderbaun \& Sollenberg (1992). Estas amostras foram separadas em duas porções, sendo uma delas utilizada para a separação das frações folha, colmo e material morto. Após separação, as duas porções (planta inteira e frações) foram secas em estufa a $55^{\circ} \mathrm{C}$ por $72 \mathrm{~h}$ e processadas em moinho tipo faca com peneira de $1 \mathrm{~mm}$ de crivo, para posteriores análises.

Em ambos os períodos experimentais, para avaliar a composição química da forragem, foram determinados os teores de proteína bruta (PB), fibra em detergente neutro (FDN) e fibra detergente ácido (FDA) conforme descrito por Silva (1990). Os teores de proteína bruta digestível (PBD) foram obtidos subtraindo-se a proteína insolúvel em detergente ácido do teor de $\mathrm{PB}$, conforme metodologia descrita por Licitra et al. (1996). Na aveia preta, foram determinadas três frações protéicas $A+B_{1}+B_{2}, B_{3}$ e $C$, conforme metodologia descrita por Licitra et al. (1996).

A digestibilidade in vitro da MS (DIVMS) foi determinada pela metodologia de Tilley \& Terry (1963), adaptada para o uso do rúmen artificial, desenvolvida por ANKOM ${ }^{\circledR}$, conforme descrito por Holden (1999). O teor de NDT foi considerado igual

R. Bras. Zootec., v.32, n.4, p.955-965, 2003 
à digestibilidade in vitro da matéria orgânica, sendo esta estimada pela fórmula: DIVMO $=-0,664+$ 1,032DIVMS (Moore et al., 1999).

A análise estatística foi realizada utilizando-se do Sistema de Análises Estatísticas e Genéticas (SAEG). Para comparação entre médias foi utilizado o teste de Tukey a $1 \%$ de probabilidade de erro. As análises para animais em crescimento e terminação foram realizadas separadamente. Para os animais em crescimento, foi utilizado o modelo: $\mathrm{Y}_{\mathrm{ij}}=\mu+\mathrm{T}_{\mathrm{i}}+\mathrm{e}_{\mathrm{ij}}$. Para os animais em terminação foi utilizado o modelo:

$$
Y_{i j}=\mu+T_{i}+R_{j}+e_{i j}
$$

em que $\mathrm{Y}_{\mathrm{ij}}$ é variável observada; $\mu$, constante geral; $\mathrm{T}_{\mathrm{i}}$, efeito do tratamento; $\mathrm{R}_{\mathrm{j}}$, efeito da raça; $\mathrm{e}_{\mathrm{ij}}$, erro aleatório associado a cada observação.

\section{Resultados e Discussão}

\section{Período de baixa produção forrageira}

Os animais mantidos em pastagem de aveia preta (PAV) apresentaram melhor $(\mathrm{P}<0,05)$ ganho médio diário (GMD: 0,64 kg/dia) quando comparados aos animais em pastagem de grama estrela roxa (GER) (GMD: -0,03 kg/dia) (Tabela 1). A perda de peso observada para os animais do tratamento GER deve-se ao baixo valor nutritivo desta forragem durante $o$ período de inverno (Tabela 4). Isto demonstra que a estrela roxa, no inverno, não proporcionou o mínimo de valor nutritivo para a mantença dos animais em regime extensivo.

Entre outubro e novembro, quando os animais dos dois tratamentos foram mantidos em pastagem de grama estrela roxa, o tratamento GER apresentou maior GMD $(0,60 \mathrm{~kg} /$ dia $)$ em relação ao PAV $(0,30 \mathrm{~kg} / \mathrm{dia})$ (Tabela 1$)$, fato que pode ser explicado pelo ganho compensatório. Vilares (1995) descreveu o ganho compensatório como resultado de taxas mais elevadas de crescimento observadas após um período de restrição alimentar. O baixo desempenho animal observado no tratamento GER desencadeou taxas maiores de ganho de peso quando as condições nutricionais da pastagem melhoraram. No entanto, a mudança de uma forrageira de melhor valor nutritivo (aveia preta) para a forrageira de menor valor nutritivo (grama estrela roxa) promoveu a diminuição da taxa de crescimento dos animais do tratamento PAV.

O PVF dos animais em PAV foi maior em relação ao PVF dos animais em GER (Tabela 1), o que significa que o ganho compensatório não foi capaz de reverter totalmente o baixo desempenho obtido durante o inverno. Para o sistema PAV houve um ganho de peso de 65 e $58 \mathrm{~kg}$ para os animais em crescimento e terminação. No sistema GER, houve um ganho de peso de 29 e $28 \mathrm{~kg}$ para os animais em crescimento e terminação. Portanto, o sistema GER associado ao ganho compensatório foi capaz de alcançar $44,62 \% \mathrm{e}$

Tabela 1 - Médias e coeficiente de variação (CV\%) para peso vivo inicial (PVI), peso vivo intermediário (PVM), peso vivo final (PVF) e ganho médio diário (GMD) para os diferentes tratamentos, no período de baixa produção forrageira

Table 1 - Means and variation coefficient (VC\%) for initial body weight (IBW), intermediate body weight (MBW) final body weight $(F B W)$ and average daily gain $(A D G)$ for different treatments in the period of low grass production

\begin{tabular}{|c|c|c|c|c|c|c|}
\hline $\begin{array}{l}\text { Parâmetros } \\
\text { Parameters }\end{array}$ & & $\begin{array}{l}\text { s em cre } \\
\text { owing st }\end{array}$ & & & $\begin{array}{l}\text { in tern } \\
\text { ing ste }\end{array}$ & \\
\hline & $\mathrm{GER}^{1}$ & $\mathrm{PAV}^{2}$ & $\mathrm{CV}$ & $\mathrm{GER}^{1}$ & $\mathrm{PAV}^{2}$ & $\mathrm{CV}$ \\
\hline $\begin{array}{l}\text { PVI }(\mathrm{kg}) \\
I B W(k g)\end{array}$ & 288 & 289 & 9,50 & 380 & 380 & 7,57 \\
\hline $\begin{array}{l}\operatorname{PVM}(\mathrm{kg}) \\
M B W(\mathrm{~kg})\end{array}$ & $297^{\mathrm{b}}$ & $340^{\mathrm{a}}$ & 8,11 & $368^{\mathrm{b}}$ & $423^{\mathrm{a}}$ & 7,96 \\
\hline $\begin{array}{l}\mathrm{GDM} 1^{3}(\mathrm{~kg} / \mathrm{dia}) \\
A D G 1^{3}(\mathrm{~kg} / \text { day })\end{array}$ & $0,13^{\mathrm{b}}$ & $0,70^{\mathrm{a}}$ & 34,36 & $-0,16^{b}$ & $0,58^{a}$ & 56,52 \\
\hline $\begin{array}{l}\operatorname{PVF}(\mathrm{kg}) \\
F B W(\mathrm{~kg})\end{array}$ & $317^{b}$ & $354^{\mathrm{a}}$ & 7,82 & $408^{b}$ & $438^{\mathrm{a}}$ & 7,11 \\
\hline $\begin{array}{l}\text { GMD } 2^{4}(\mathrm{~kg} / \mathrm{dia}) \\
A D G 2^{4}(\mathrm{~kg} / \text { day })\end{array}$ & $0,41^{\mathrm{a}}$ & $0,28^{\mathrm{a}}$ & 57,10 & $0,79^{a}$ & $0,31^{\mathrm{b}}$ & 39,85 \\
\hline $\begin{array}{l}\text { GDM Total (kg/dia) } \\
\text { Total } A D G(\mathrm{~kg} / \text { day })\end{array}$ & $0,24^{b}$ & $0,53^{\mathrm{a}}$ & 36,10 & $0,23^{b}$ & $0,47^{\mathrm{a}}$ & 32,59 \\
\hline
\end{tabular}

R. Bras. Zootec., v.32, n.4, p.955-965, 2003 
$48,28 \%$ do ganho obtido em PAV para os animais em crescimento e terminação, respectivamente.

Moreira et al. (2001b) observaram, no inverno, em pastagem de grama estrela roxa, GDM de $0,06 \mathrm{~kg} /$ dia para animais em terminação, valor semelhante ao obtido neste experimento. Em pastagem de aveia preta e ervilha forrageira, Grise (2000) observou GMD de 1,02 kg/dia para bezerros com peso inicial médio de $150 \mathrm{~kg}$, em condições de disponibilidade de $\mathrm{MS} / \mathrm{ha}$ semelhante a este experimento. $\mathrm{O}$ maior GMD observado por Grise (2000) poderia ter ocorrido em função do manejo adotado, uma vez que os animais avaliados por Grise (2000) permaneceram exclusivamente em pastagem de inverno durante o período experimental.

A disponibilidade de MS/ha, para a pastagem de aveia preta e grama estrela roxa, esteve acima de $2000 \mathrm{~kg} / \mathrm{ha}$ (Tabela 2). Este valor foi estipulado por Minson (1990) como sendo o mínimo para que não ocorra diminuição no consumo da forragem. No entanto, para a grama estrela roxa, a maior parte da forragem estava na forma de material morto (60\%), sendo esta fração caracterizada pelo baixo consumo pelos animais (Carvalho et al., 2001). Assim, apesar da disponibilidade total de MS estar acima de 2000 $\mathrm{kg} / \mathrm{ha}$, a disponibilidade de folhas era de $280 \mathrm{~kg} / \mathrm{ha}$, o que possivelmente prejudicou o consumo da forragem e, conseqüentemente, o desempenho animal.

A produção total de matéria seca da aveia preta foi de $5945 \mathrm{~kg} / \mathrm{ha}$. Este valor foi superior ao obtido por Canto et al. (1997) de $4545 \mathrm{~kg} \mathrm{MS} /$ ha para pastagem de aveia preta adubada com $100 \mathrm{~kg}$ de N/ha. Esta diferença pode ter ocorrido em função das condições climáticas ou da disponibilidade de nutrientes no solo.

Na Tabela 2, estão demonstradas as taxas de lotação para os piquetes de aveia preta e grama estrela roxa. Os animais do tratamento PAV eram mantidos 4 horas diárias na pastagem de aveia preta e 20 horas diárias na pastagem de grama estrela roxa. Assim, quando se considera a taxa de lotação nos dois piquetes (aveia + grama estrela), o valor obtido foi de 1,14 UA/ha.

Apenas o tratamento PAV apresentou ganho por área no período entre $07 / 07$ a 18/09, enquanto que, para o tratamento GER, houve perda de peso vivo/ha (Tabela 2). Para o cálculo do GPV/ha para o tratamento PAV, foi considerada apenas a área de aveia preta. Uma vez que os animais permaneceram em pastagem de aveia preta e grama estrela roxa, quando se considera as duas áreas (aveia -4 ha + grama estrela
Tabela 2 - Disponibilidade de matéria seca total (MS), taxa de lotação (TL) e ganho de peso vivo por hectare (GPV/ha) para os tratamentos no período de baixa produção forrageira

Table 2 - Total dry matter availability (DM), stocking rate (SR) and body weight gain in hectare (BWG) for treatments in the period of low grass production

\begin{tabular}{lccc}
\hline $\begin{array}{l}\text { Parâmetros } \\
\text { Parameters }\end{array}$ & PAV $^{1}$ & GER-I & GER-P \\
\hline MS (kg/ha) & 2492 & 3721 & 3649 \\
$\begin{array}{l}\text { DM (kg/ha) } \\
\text { TL }(\mathrm{UA} / \mathrm{ha})\end{array}$ & 3,98 & 0,72 & 0,82 \\
$\begin{array}{l}\text { SR }(\mathrm{AU} / \mathrm{ha}) \\
\mathrm{GPV}(\mathrm{kg} / \mathrm{ha})\end{array}$ & 233,60 & $-1,38$ & 25 \\
$B W G(\mathrm{~kg} / \mathrm{ha})$ & & & \\
\hline
\end{tabular}

${ }^{1} \mathrm{PAV}$ :pastagem de aveia; ${ }^{2} \mathrm{GER}-\mathrm{I}$ : grama estrela roxa de 07/0718/09/2000; ${ }^{3}$ GER-P:18/09-08/11/2000.

1 PAV: oat pasture; ${ }^{2}$ GER-I: violet star grass 07/07- 09/18/2000; ${ }^{3}$ GER-P: $09 / 18-11 / 08 / 2000$.

- $10 \mathrm{ha}$ ), o GPV/ha foi de $66,74 \mathrm{~kg}$. No período entre 18/09 e 08/11, a GER apresentou GPV/ha de $25 \mathrm{~kg}$.

Restle et al. (1998) obtiveram $669 \mathrm{~kg} \mathrm{PV} / \mathrm{ha}$ em pastagem de aveia preta e azevém, valor este superior ao obtido neste experimento. O maior período de pastejo (103 dias) associado ao maior GMD $(1,60 \mathrm{~kg} /$ dia) e taxa de lotação semelhante (3,39 UA/ha) resultaram em melhor GPV/ha. No entanto, estes autores trabalharam com pastagem consorciada de aveia preta e azevém, o que possibilita que o período de pastejo seja mais prolongado, resultando em maior GPV/ha.

A maior parte dos trabalhos desenvolvidos em pastagem de inverno é proveniente da região sul do Brasil. Nesta região, o principal fator limitante da produção forrageira é a queda da temperatura e luminosidade. No entanto, para a região norte do Paraná, a limitação para a produção forrageira se dá em função da queda na temperatura, luminosidade e pluviosidade. Assim, o azevém não é utilizado nesta região, em função de sua maior exigência em umidade (Keplin, 1996).

A aveia preta apresentou alto valor nutritivo (Tabela 3). Este alto valor nutritivo possibilitou melhor desempenho animal nesta pastagem, durante o período do inverno. Os teores de PB, FDN e FDA foram diferentes entre os dias de coleta. Houve o aumento nos teores de FDN e FDA e diminuição nos teores de PB com a maturidade da forragem.

Os níveis de FDN e FDA observados nas três primeiras coletas foram semelhantes ao descrito por Moreira et al. (2001a), avaliando a mesma espécie vegetal, em parcelas. No entanto, nas últimas coletas, 
Tabela 3 - Teores de fibra em detergente neutro, fibra em detergente ácido, proteína bruta (\% na matéria seca) e fracionamento da proteína bruta pelo sistema Cornell (\% da PB) da pastagem de aveia preta nos períodos experimentais

Table 3 - Neutral detergent fiber, acid detergent fiber, crude protein (\% in dry matter) and crude protein fractioning by Cornell system (\% of CP) of black oat pasture in experimental periods

\begin{tabular}{|c|c|c|c|c|c|c|}
\hline $\begin{array}{l}\text { Dia de coleta } \\
\text { Day of collection }\end{array}$ & $\begin{array}{l}\text { FDN } \\
N D F\end{array}$ & $\begin{array}{l}\text { FDA } \\
A D F\end{array}$ & $\begin{array}{l}\mathrm{PB} \\
C P\end{array}$ & $\mathrm{~A}+\mathrm{B}_{1}+\mathrm{B}_{2}$ & $\mathrm{~B}_{3}$ & $\mathrm{C}$ \\
\hline 01/07 & 40,50 & 23,20 & 21,01 & 73,82 & 14,80 & 11,38 \\
\hline $24 / 07$ & 42,09 & 25,51 & 18,08 & 73,05 & 14,01 & 12,94 \\
\hline 07/08 & 48,27 & 30,15 & 15,59 & 70,75 & 14,11 & 15,14 \\
\hline $23 / 08$ & 56,39 & 34,87 & 12,13 & 64,14 & 13,93 & 21,93 \\
\hline $20 / 09$ & 69,44 & 43,59 & 8,74 & 40,73 & 20,48 & 38,79 \\
\hline
\end{tabular}

o teor de FDN e FDA foi superior, o que pode ser decorrente da maior maturidade da planta, uma vez que ocorre aumento no conteúdo de parede celular com a maturidade da forragem (Dove, 1998).

Roso et al. (1999) observaram diminuição no teor de PB da aveia preta em função da maturidade da planta, com valores entre 28,6 a 19,4\%. Estes teores foram superiores ao obtido neste experimento, o que pode ser decorrente do maior nível de adubação nitrogenada utilizada (175 kg N/ha), uma vez que ocorre aumento no teor de PB da aveia preta em função do nível de adubação com nitrogênio (Moreira et al., 2001a).

Do fracionamento da PB da aveia preta, nas três primeiras coletas, aproximadamente $70 \%$ da $\mathrm{PB}$ não estava associada ao componente de parede celular da planta, representando as frações protéicas de alta a média degradabilidade no rúmen (NRC, 1996). Nesta diretriz, considerando que os teores de PB são elevados na aveia preta e que a PB da aveia apresenta de média a alta degradabilidade, podem estar ocorrendo perdas de nitrogênio, devido ao desbalanço entre proteína e energia no rúmen.

Houve aumento na proporção de $\mathrm{PB}$ associada à FDA (Fração C), em função da maior maturidade da planta. Gonçalves (2001), avaliando pastagens do gênero Cynodon, também observaram aumento na proporção de $\mathrm{PB}$ associada à FDA em função da maturidade da pastagem. Assim, em estádios mais avançados de desenvolvimento da forragem, associado à diminuição nos teores de $\mathrm{PB}$, ocorreu aumento na proporção de proteína associada à FDA, sendo esta fração protéica não digerida pelos microrganismos do rúmen e, portanto, não aproveitada pelo animal.

A composição química da grama estrela roxa mostrou o baixo valor nutritivo desta forrageira durante o período do inverno (Tabela 4). Os níveis de PB da forragem assim como das frações folha e colmo foram inferiores a 7\%/MS, sendo este o mínimo para que não haja prejuízo da utilização da forragem por parte dos microrganismos ruminais (Van Soest, 1994). Assim, o desempenho animal estará prejudicado em função do baixo teor de $\mathrm{PB}$ na pastagem e dos altos níveis de FDA, o que pode prejudicar o consumo voluntário da forragem (Noller et al., 1997) e, conseqüentemente, o desempenho animal.

Houve diminuição na DIVMS com a maturidade da pastagem de aveia preta (Tabela 5). Canto et al. (1997), em pastagem de aveia preta, também observaram diminuição da DIVMS em função da maturidade da planta. Esta diminuição ocorre em função do aumento no conteúdo de parede celular, principalmente a lignina, o que irá resultar na menor digestibilidade da forragem (Dove, 1998).

Tabela 4 - Teores de fibra em detergente neutro, fibra em detergente ácido, proteína bruta e proteína bruta digestível da grama estrela roxa (\% na matéria seca)

Table 4 - Neutral detergent fiber, acid detergent fiber, crude protein and digestible crude protein of violet star grass pasture (\% in dry matter)

\begin{tabular}{|c|c|c|c|c|}
\hline & $\begin{array}{l}\text { FDN } \\
N D F\end{array}$ & $\begin{array}{l}\text { FDA } \\
A D F\end{array}$ & $\begin{array}{l}\text { PB } \\
C P\end{array}$ & $\begin{array}{l}\text { PBD } \\
D C P\end{array}$ \\
\hline 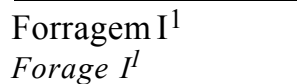 & 82,03 & 50,65 & 4,90 & 1,94 \\
\hline $\begin{array}{l}\text { Folhas }+ \text { colmos } \mathrm{I}^{1} \\
\text { Leaves }+ \text { steams } I^{1}\end{array}$ & 79,87 & 49,03 & 6,51 & 3,12 \\
\hline $\begin{array}{l}\text { Forragem } \mathrm{P}^{2} \\
\text { Forage } P^{2}\end{array}$ & 80,23 & 50,59 & 5,23 & 2,29 \\
\hline $\begin{array}{l}\text { Folhas }+ \text { colmos } \mathrm{P}^{2} \\
\text { Leaves }+ \text { steams } P^{2}\end{array}$ & 69,46 & 40,12 & 7,69 & 5,95 \\
\hline
\end{tabular}


Tabela 5 - Digestibilidade in vitro da matéria seca (DIVMS), nutrientes digestíveis totais (NDT) e relação entre o NDT e a PB da aveia preta

Table 5 - In vitro dry matter digestibility (IVDMD), total digestive nutrients (TDN) and relationship between $T D N$ and $C P$ of black oat

\begin{tabular}{lccc}
\hline $\begin{array}{l}\text { Dia de coleta } \\
\text { Day of collection }\end{array}$ & $\begin{array}{c}\text { DIVMS } \\
\text { IVDMD }\end{array}$ & $\begin{array}{c}\text { NDT } \\
\text { TDN }\end{array}$ & $\begin{array}{c}\text { NDT:PB } \\
\text { TDN:CP }\end{array}$ \\
\hline Aveia - 01/07 & 91,00 & 94,59 & 4,50 \\
Aveia - 24/07 & 90,99 & 93,24 & 5,16 \\
Aveia - 07/08 & 81,79 & 83,74 & 5,37 \\
Aveia - 23/08 & 81,34 & 83,28 & 6,87 \\
Aveia-20/09 & 62,92 & 64,27 & 7,35 \\
GER I $^{1}$ & 44,76 & 45,53 & 9,29 \\
GERP $^{2}$ & 41,57 & 42,24 & 8,08 \\
\hline
\end{tabular}

107/07-18/09; 218/09-08/11.

$107 / 07-09 / 18 ;{ }^{2} 09 / 18-11 / 08$

A relação entre o teor de NDT e PB da forragem foi inferior a 7 para a pastagem de aveia preta e superior para a grama estrela roxa. Moore et al. (1999) levantaram a hipótese de que, quando esta relação estiver acima de 7 , está havendo deficiência de proteína em relação à energia. Por outro lado, quando esta relação for menor que 7, o déficit é de energia. Neste caso, a aveia preta apresentou déficit de energia e a grama estrela roxa apresentou déficit de proteína, durante o período avaliado, o que resultou no baixo ganho animal obtido para a grama estrela roxa. Ganhos superiores poderiam ser obtidos em pastagem de aveia preta caso houvesse o melhor balanço entre proteína e energia na dieta.

Período de alta produção forrageira

Durante o período de novembro a março, os GMD dos animais em crescimento do sistema GER + MOM
$(0,88 \mathrm{~kg} / \mathrm{dia})$ foi superior $(\mathrm{P}<0,01)$ ao $\mathrm{PAV}+\mathrm{MOM}$ $(0,58 \mathrm{~kg} / \mathrm{dia})$. Este maior GDM obtido no verão foi capaz de compensar o maior GMD obtido pelos animais do tratamento PAV + MOM no período do inverno, de forma que, ao final do período experimental, não houve diferença $(P>0,05)$ no $P V F$ dos animais dos dois sistemas avaliados (Tabela 6).

O maior GMD observado para os animais do sistema GER + MOM ocorreu em função do ganho compensatório. Uma vez que os animais no sistema GER + MOM apresentaram baixo ganho de peso no período do inverno, estes foram capazes de responder com maior GMD quando as condições ambientais foram favoráveis para promover maior desempenho animal. No entanto, os animais mantidos em PAV apresentaram maior GMD no inverno, de forma que, quando foram manejados em capim-Mombaça, o crescimento animal foi prejudicado, em função da menor qualidade nutricional do capim-Mombaça (Tabela 9).

Arrigoni et al. (1998) submeteram animais em crescimento por 84 dias de restrição alimentar, para apresentarem GMD de $0,8 \mathrm{~kg} /$ dia. Os animais com consumo ad libitum apresentaram GMD de 1,0 kg/ dia. Após este período, os animais foram terminados em confinamento, de forma que, após 61 dias, não houve diferença no peso vivo final dos animais, uma vez que os animais que passaram pela restrição alimentar apresentaram ganho compensatório, alcançando, assim, o mesmo peso dos animais alimentados ad libitum.

Observa-se que o período necessário para a recuperação dos animais deste experimento foi superior ao tempo necessário obtido por Arrigoni et al.

Tabela 6 - Médias e coeficiente de variação (CV\%) para peso vivo inicial (PVI), peso vivo final (PVF) e ganho médio diário (GMD) para novilhos em crescimento, mantidos em diferentes sistemas de produção no período de alta produção forrageira

Table 6 - Means and variation coeficient (VC\%) for initial body weight (IBW), final body weight (FBW) and average daily gain (ADG) for growing steers, kept in different production systems, during the period of high grass production

\begin{tabular}{|c|c|c|c|c|c|c|}
\hline $\begin{array}{l}\text { Parâmetros } \\
\text { Parameters }\end{array}$ & $\mathrm{GER}+\mathrm{MOM}^{1}$ & $\mathrm{PAV}+\mathrm{MOM}^{2}$ & $\mathrm{PAV}+\mathrm{MIL}^{3}$ & $\begin{array}{l}\mathrm{CV} \\
V C\end{array}$ & CT $1^{4}$ & $\mathrm{CT} 2^{5}$ \\
\hline $\begin{array}{l}\mathrm{PVI}(\mathrm{kg}) \\
I B W(\mathrm{~kg})\end{array}$ & 304 & 353 & 356 & 9,47 & $\mathrm{P}<0,01$ & NS \\
\hline $\begin{array}{l}\mathrm{PVF}(\mathrm{kg}) \\
F B W(\mathrm{~kg})\end{array}$ & 397 & 414 & 447 & 8,46 & NS & $\mathrm{P}<0,01$ \\
\hline GMD (kg/dia) & 0,88 & 0,58 & 0,88 & 22,54 & $\mathrm{P}<0,05$ & $\mathrm{P}<0,05$ \\
\hline
\end{tabular}

$A D G(\mathrm{~kg} /$ day $)$

${ }^{1}$ GER + MOM: grama estrela roxa no inverno e capim mombaça no verão; ${ }^{2}$ PAV + MOM: pastagem de aveia preta no inverno e capim mombaça no verão; ${ }^{3} \mathrm{PAV}+\mathrm{MIL}$ : pastagem de aveia preta no inverno e pastagem de milheto no verão; ${ }^{4} \mathrm{CT}$ 1: contraste entre GER + MOM e PAV + MOM: ${ }^{5} \mathrm{CT}$ 2: contraste entre PAV + MOM e PAV + MIL.

1 GER + MOM: violet stargrass during winter and mombaça during summer; ${ }^{2} P A V+M O M$ : black oat pasture during winter and mombaça during summer; ${ }^{3} P A V$ + MIL: black oat pasture during winter and millet during: ${ }^{4} \mathrm{CT}$ 1: contrast beetwen GER + MOM and PAV + MOM; ${ }^{5} \mathrm{CT}$ 2: contrast beetwen PAV + MOM and $P A V+$ MIL.

R. Bras. Zootec., v.32, n.4, p.955-965, 2003 
(1998). Esta diferença ocorreu em função da severidade da restrição alimentar. Estes mesmos autores trabalharam com restrição que propiciasse GMD de $0,8 \mathrm{~kg} / \mathrm{dia}$. No entanto, neste experimento, a restrição foi maior, de forma que o GMD obtido durante a restrição foi de $0,13 \mathrm{~kg} /$ dia. Estes dados confirmam o pressuposto levantado por Vilares (1995) de que, quanto maior a severidade da restrição, maior será o tempo necessário para a recuperação do peso dos animais.

Em relação à forrageira utilizada no verão, o milheto propiciou, para os animais em crescimento, melhor ( $\mathrm{P}<0,05)$ GMD $(0,88 \mathrm{~kg} /$ dia $)$ quando comparado ao capim-Mombaça $(0,58 \mathrm{~kg} /$ dia $)$ (Tabela 6$)$. Assim, o PVF dos animais no sistema PAV + MIL $(447 \mathrm{~kg})$ foi superior $(\mathrm{P}<0,01)$ aos animais do sistema PAV + MOM (414 kg) (Tabela 6). O melhor desempenho animal observado na pastagem de milheto ocorreu em função do melhor valor nutricional, quando comparado ao capim-Mombaça (Tabela 9).

Moojen et al. (1999) observaram GMD de 0,55 a $0,76 \mathrm{~kg} /$ dia para animais com peso inicial médio de $230 \mathrm{~kg}$, mantidos em pastagem de milheto adubada com níveis de 0 a $300 \mathrm{~kg}$ de N/ha. O GMD obtido neste experimento foi superior ao obtido por Moojen et al. (1999) e semelhante ao observado por Cóser \& Maraschin (1983), avaliando bovinos com peso inicial médio de $190 \mathrm{~kg}$, onde observaram GMD de $0,78 \mathrm{~kg} /$ dia em pastagem de milheto.

Para os animais em terminação, o PVI dos animais do sistema PAV + MIL foi superior $(\mathrm{P}<0,05)$ ao PVI do sistema GER + MIL (Tabela 7). Esta diferença ocorreu em função do maior GMD observado durante o inverno para os animais mantidos em pastagem de aveia preta. No verão, quando estes animais foram manejados em pastagem de milheto, o GMD do sistema GER + MIL foi superior $(\mathrm{P}<0,01)$ ao sistema PAV + MIL (Tabela 7). Este melhor desempenho ocorreu em função do ganho compensatório, comportamento este semelhante ao obtido com os animais em crescimento, conforme já detalhado anteriormente.

Os sistemas PAV + MIL e PAV + MOM não apresentaram diferença $(\mathrm{P}>0,05)$ para o PVI, GMD e PVF (Tabela 7). Assim, para animais em terminação mantidos em pastagem de aveia preta no inverno, o uso de pastagem de milheto ou capim-Mombaça resultou em desempenho animal semelhante, apesar do melhor valor nutritivo observado para a pastagem de milheto (Tabela 9).

Da mesma forma, não houve diferença $(\mathrm{P}>0,05)$ entre os sistemas GER + GER ou GER + MIL, para o PVI, GMD e PVF (Tabela 7). Neste sentido, o melhor valor nutricional observado para a pastagem de milheto (Tabela 9) não resultou em melhor desempenho para os animais em terminação.

Tabela 7 - Médias e coeficiente de variação (CV\%) para peso vivo inicial (PVI), peso vivo final (PVF), ganho médio diário $(G M D)$, rendimento de carcaça $(R C)$ e peso de carcaça quente (PCQ) para novilhos em terminação, mantidos em diferentes sistemas de produção no período de alta produção forrageira

Table 7 - Means and variation coeficient (VC\%) for initial body weight (IBW), final body weight (FBW), average daily gain (ADG), carcass yield $(\mathrm{CW})$ and hot carcass weight $(\mathrm{HCW})$ finishing steers, kept in different production systems during the period of high grass production

\begin{tabular}{|c|c|c|c|c|c|c|c|c|}
\hline $\begin{array}{l}\text { Parâmetros } \\
\text { Parameters }\end{array}$ & GER + GER $^{1}$ & GER+MIL ${ }^{2}$ & $\mathrm{PAV}+\mathrm{MIL}$ & $3 \mathrm{PAV}+\mathrm{MOM}^{4}$ & $\begin{array}{l}\mathrm{CV} \\
V C\end{array}$ & $\mathrm{CT} 1^{5}$ & $\mathrm{CT} 2^{6}$ & $\mathrm{CT}^{7}$ \\
\hline PVI (kg) & 403 & 397 & 437 & 440 & 8,63 & NS & $\mathrm{P}<0,05$ & NS \\
\hline $\begin{array}{l}I B W(\mathrm{~kg}) \\
\mathrm{PVF}(\mathrm{kg}) \\
F B W(\mathrm{~kg})\end{array}$ & 443 & 434 & 442 & 445 & 8,89 & NS & NS & NS \\
\hline $\begin{array}{l}\mathrm{GMD}(\mathrm{kg}) \\
A D G(\mathrm{~kg} / \text { day })\end{array}$ & 0,71 & 0,66 & 0,08 & 0,10 & 45,52 & NS & $\mathrm{P}<0,01$ & NS \\
\hline $\begin{array}{l}\mathrm{RC}(\%) \\
C Y(\%)\end{array}$ & 54,07 & 53,84 & 55,51 & 53,49 & 4,63 & NS & NS & NS \\
\hline $\begin{array}{l}\mathrm{PCQ}(\mathrm{kg}) \\
\mathrm{HCW}(\mathrm{kg})\end{array}$ & 239 & 234 & 245 & 238 & 10,65 & NS & NS & NS \\
\hline
\end{tabular}

${ }^{1}$ GER + GER: grama estrela roxa no inverno e verão; ${ }^{2}$ GER + MIL: grama estrela roxa no inverno e pastagem de milheto no verão; ${ }^{3}$ PAV + MIL: pastagem de aveia preta no inverno e pastagem de milheto no verão; ${ }^{4} \mathrm{PAV}+\mathrm{MOM}$ : pastagem de aveia preta no inverno e capim mombaça no verão; ${ }^{5} \mathrm{CT} 1$ : contraste entre GER + GER e GER + MIL; ${ }^{6} \mathrm{CT}$ 2: contraste entre GER + MIL e PAV + MIL; ${ }^{7} \mathrm{CT} 3:$ contraste entre PAV + MIL e PAV + MOM.

${ }^{1}$ GER + GER: violet star grass during winter summer; ${ }^{2}$ GER + MIL: violet star grass during winter and millet pasture during summer; ${ }^{3} P A V+M I L:$ black oat pasture during winter and millet during; ${ }^{4} P A V+M O M$ : black oat pasture during winter and mombaça during summer; ${ }^{5} C T$ 1: contrast beetwen GER + GER and GER + MIL; ${ }^{6} C T$ 2: contrast beetwen GER + MIL and PAV + MIL; ${ }^{7} C T$ 3: contrast beetwen PAV + MIL and PAV + MOM.

R. Bras. Zootec., v.32, n.4, p.955-965, 2003 
O RC e PCQ dos sistemas de produção avaliados foram semelhantes $(\mathrm{P}>0,05)$ (Tabela 7). O RC apresentou valor médio de $54,2 \%$. Este valor é inferior ao obtido por Prado et al. (2000), em que animais 1/2 zebuínos x $1 / 2$ taurinos, terminados em confinamento, apresentaram RC de $57,1 \%$. Por outro lado, o rendimento foi superior ao valor de $52,3 \%$ para animais inteiros, $1 / 2$ zebuínos $x 1 / 2$ taurinos, obtido por Leme et al. (2000).

Ryan (1990) atribuiu parte do efeito do ganho compensatório ao aumento no conteúdo de retículo rúmen. No entanto, o mesmo autor salienta que o efeito do enchimento ruminal sobre o ganho compensatório se limita às 2 ou 3 primeiras semanas após a alimentação ser restabelecida.

Assim, quando da avaliação de sistemas de produção de bovinos de corte, é necessário o estudo dos sistemas em todas as etapas de produção, uma vez que o manejo adotado durante o inverno influenciou o desempenho animal no verão, conforme já salientado por Drouillard \& Kuhl (1999).

Nussio et al. (2001), em revisão sobre suplementação em pastagens, observaram que o menor ganho de peso obtido durante o inverno, em função da restrição alimentar, é compensado pelos animais durante o verão, de forma que, no final deste período, o peso dos animais que sofreram ou não restrição alimentar é semelhante.

A disponibilidade de $\mathrm{MS} / \mathrm{ha}$ e a taxa de lotação foram semelhantes nas diferentes pastagens utilizadas (Tabela 8). No entanto, a disponibilidade de folhas por hectare foi inferior na pastagem de grama estrela roxa, o que se deve em função da baixa proporção de folhas observada (Tabela 8 ).

$\mathrm{O}$ GPV/ha para as pastagem de milheto foi de $270 \mathrm{~kg}$ (Tabela 8), valor inferior ao obtido por Cóser $\&$ Maraschin (1983) e por Moojen et al. (1999). Estes

Tabela 8 - Disponibilidade de MS e de folhas por hectare e taxa de lotação utilizada nas pastagens durante o período de alta produção forrageira

Table 8 - Dry matter (DM/ha) and leaf availability (LEA/ha) per hectare and stocking rate (SR) in pastures during the period of high grass production

\begin{tabular}{lcccc}
\hline & MS/ha(kg) & FOL/ha(kg) & TL(UA/ha) & BWG/ha \\
& DM/ha (kg) & $L E A / h a(k g)$ & AU/ha & GPV/ha \\
\hline GER & 3617 & 685 & 2,03 & 223 \\
MOM & 3783 & 1629 & 2,29 & 266 \\
MIL & 3888 & 2388 & 2,77 & 270 \\
\hline
\end{tabular}

R. Bras. Zootec., v.32, n.4, p.955-965, 2003 autores observaram ganhos de 245 a $665 \mathrm{~kg} / \mathrm{ha}$ para pastagens adubadas com níveis de 0 a $300 \mathrm{~kg}$ de N/ ha, enquanto que aqueles observaram ganhos de 401 $\mathrm{kg} / \mathrm{ha}$ em pastagens de milheto fertilizadas com $60 \mathrm{~kg}$ de N/ha.

Neste experimento, o piquete utilizado para a pastagem de milheto apresentava 19 ha de área, o que dificultou o manejo, uma vez que o pastejo não foi homogêneo em toda a área experimental, de forma que em alguns pontos ocorreu superpastejo, a ponto de rebaixar a pastagem a $5 \mathrm{~cm}$ do solo e, em outros pontos, houve o subpastejo, onde o não pastejo nestas áreas fez com que a planta se desenvolvesse, chegando a produzir sementes. Estas plantas, já em estado reprodutivo, não foram mais consumidas pelos animais, o que prejudicou a possibilidade de manter maior lotação na pastagem e consequentemente, melhor GPV/ha.

As forrageiras utilizadas no experimento apresentaram bom valor nutritivo (Tabela 9), o que propiciou o bom desempenho animal observado no período. A pastagem de milheto apresentou melhor qualidade nutricional em relação à pastagem de grama estrela roxa e capim-Mombaça, com maiores teores de DIVMS, PB e PBD, associado a menores níveis de FDN e FDA.

A PB pastagem de Mombaça foi inferior ao descrito por Machado et al. (1998), onde foram observados valores de $13 \%$. Os níveis de FDN e FDA observados por Machado et al. (1998) foram superiores ao obtido neste experimento. No entanto, estes autores avaliaram o capim em intervalos de corte de 35 dias, enquanto que neste experimento a avaliação foi feita em pastejo. Assim, com intervalos de 35 dias, possivelmente a forragem estava mais madura e, quanto maior a maturidade da planta, maior será o nível de conteúdo de parede celular (Dove, 1998).

$\mathrm{O}$ teor de $\mathrm{PB}$ do milheto foi semelhante ao observado por Pereira et al. (1993) com valores de $16,7 \%$ de PB. No entanto o nível de FDN obtido foi inferior a $68 \%$ observado pelos mesmos autores. A DIVMS do milheto foi superior à observada por Silva et al. (1995) com valor de $70 \%$. No entanto, o nível de FDN neste experimento foi inferior a $63 \%$, obtido pelos mesmos autores. Assim, o maior nível de FDN justifica a menor DIVMS, uma vez que a digestibilidade da forragem diminui, à medida que aumenta o conteúdo de parede celular (Dove, 1998). 
Tabela 9 - Digestibilidade in vitro da matéria seca (DIVMS), proteína bruta (PB), proteína bruta digestível (PBD), fibra em detergente neutro (FDN) e fibra em detergente ácido (FDA) da forragem utilizada durante o período de alta produção forrageira ( $\%$ na matéria seca)

Table 9 - In vitro dry matter digestibility (IVDMD), crude protein $(C P)$, digestible crude protein $(D C P)$, neutral detergent fiber (NDF) and acid detergent fiber (ADF) of forage used during the period of high grass production (\% in dry matter)

\begin{tabular}{|c|c|c|c|c|}
\hline & $\begin{array}{l}\text { DIVMS }^{1} \\
I_{V D M D^{1}}\end{array}$ & $\begin{array}{l}\mathrm{PB} \\
C P\end{array}$ & $\begin{array}{ll}\text { PBD } & \text { FDN } \\
D C P & N D F\end{array}$ & $\begin{array}{l}\text { FDA } \\
A D F\end{array}$ \\
\hline GER (folha + colmo) & 55,08 & 8,90 & $6,35 \quad 65,00$ & 40,35 \\
\hline $\begin{array}{l}\text { GER (leaf }+ \text { steam }) \\
\text { MOM (folha) } \\
\text { MOM (leaf) }\end{array}$ & 60,34 & 9,53 & $6,88 \quad 64,15$ & 39,19 \\
\hline $\begin{array}{l}\text { MIL (folha) } \\
\text { MIL (leaf) }\end{array}$ & 80,52 & 17,62 & $14,4454,13$ & 31,67 \\
\hline
\end{tabular}

${ }^{1}$ DIVMS: análise feita da planta inteira.

1 IVDMD: all forage analysis.

\section{Conclusões}

A utilização de pastagem de aveia preta possibilitou melhor desempenho animal, durante o inverno quando comparada à pastagem de grama estrela roxa.

Os animais mantidos em pastagem de aveia preta no período do inverno apresentaram menor desempenho no verão, de forma que, o peso dos animais, mantidos em pastagem de grama estrela roxa ou com acesso à pastagem de aveia preta durante o período do inverno, foram semelhantes após o período de verão.

No verão, a pastagem de milheto propiciou melhor desempenho para bovinos em crescimento. No entanto, para animais em terminação, o desempenho em pastagem de grama estrela roxa, capim-Mombaça e milheto foram semelhantes.

Quando da avaliação de sistemas de produção de bovinos de corte, é necessária a avaliação de todo o ciclo de produção, uma vez que o manejo adotado em determinado período do ano terá influência sofre o desempenho animal no período subseqüente.

\section{Literatura Citada}

ARRIGONI, M.B.; VIEIRA, P.F.; SILVEIRA, A.C. et al. Efeitos da restrição alimentar no desempenho de bovinos jovens confinados. Pesquisa Agropecuária Brasileira, v.33, n.6, p.987-992, 1998.

BÜRGI, R. Confinamento estratégico. In: REUNIÃO ANUAL DA SOCIEDADE BRASILEIRA DE ZOOTECNIA, 38., 2001, Piracicaba. Anais... Piracicaba: Sociedade Brasileira Zootecnia, 2001. p.276-283.
CAMPBELL, A.G. Grazed pastures parameters: I. Pasture dry matter production and availability in a stocking rate and grazing management experiment with dairy cows. Journal of Agricultural Science, v.67, n.2, p.211-216, 1966.

CANTO, M.W.; RESTLE, J.; QUADROS, F.L.F. et al. Produção animal em pastagens de aveia (Avena strigosa Schreb) adubada com nitrogênio ou em mistura com ervilhaca (Vicia sativa L.). Revista Brasileira de Zootecnia, v. 26, n. 2, p. 396-402, 1997.

CARVALHO, P.C.F.; RIBEIRO FILHO, H.M.N.; POLI, C.H.E.C. et al. Importância da estrutura da pastagem na ingestão e seleção de dietas pelo animal em pastejo. In: SOCIEDADE BRASILEIRA DE ZOOTECNIA (Ed.) A produção animal na visão dos brasileiros. Piracicaba: Fundação de Estudos Agrários Luiz de Queiroz, 2001. p.853-871.

CÓSER, A.C.; MARACHIN, G.E. Desempenho animal em pastagens de milheto comum e sorgo. Pesquisa Agropecuária Brasileira, v.18, n.4, p.421-426, 1983.

DOVE, $H$. The ruminant, the rumen and the pasture resource: nutrient interactions in the grazing animal. In: HODGSON, J.; ILLIUS, A.W. (Eds.) The ecology and management of grazing systems. 2.ed. London: CAB International, 1998. 466p.

DROUILLARD, J.S.; KUHL, G.L. Effects of previous grazing nutrition and management on feedlot performance of cattle. Journal of Animal Science, v.77, Suppl. 2, p.136-146, 1999.

GARDNER, A.L. Técnicas de pesquisa em pastagens e aplicabilidade de resultados em sistemas de produção. Brasília: IICA, EMBRAPA - CNPGL, 1986. 197p.

GONÇALVES, G.D. Avaliação nutricional de gramíneas do gênero Cynodon. Maringá: Universidade Estadual de Maringá, 2001. 91p. Dissertação (Mestrado em Zootecnia) - Universidade Estadual de Maringá, 2001.

GRISE, M.M. Avaliação animal e da pastagem de aveia preta (Avena strigosa Schreb.) consorciada à ervilha forrageira (Pisium arvense L.) em diferentes alturas, na região do arenito caiuá. Maringá: Universidade Estadual de Maringá, 2000. 72p. Dissertação (Mestrado em Zootecnia) - Universidade Estadual de Maringá, 2000.

HOLDEN, L.A. Comparison of methods of in vitro dry matter digestibility for ten feeds. Journal of Dairy Science, v.82, n.8, p.1791-1794, 1999.

HOLDERBAUN, J.F.; SOLLENBERG, K.H. Canopy structure and nutritive value of limpograss pastures during mid-summer to early autumn. Agronomy Journal, v.84, n.1, p.11-16, 1992.

KEPLIN, L.A.S. Azevém. In: MONTEIRO, A.L.G. (Ed.) Forragicultura no Paraná. Londrina: IAPAR, 1996. p.235.

KLINGMAN, D.L.; MILES, S.R.; MOTT, G.O. The cage method for determining consumption and yield of pasture herbage. Journal of American Society of Agronomy, v.35, p.739-746, 1943.

LEME, P.R.; BOIN, C.; MARGARIDO, R.C.C. et al. Desempenho em confinamento e características de carcaça de bovinos machos de diferentes cruzamentos abatidos em três faixas de peso. Revista Brasileira de Zootecnia, v.29, n.6, sup.2, p.2347-2353, 2000.

LICITRA, G.; HERNANDEZ, T.M.; Van SOEST, P.J. Standardization of procedures for nitrogen fractionation of ruminant feed. Animal Feed Science and Technology, v.57, n.4, p.347-358, 1996. 
MACHADO, A.O.; CECATO, U.; MIRA, R.T. et al. Avaliação da composição química e digestibilidade in vitro da matéria seca de cultivares e acessos de Panicum maximum Jacq. Sob duas alturas de corte. Revista Brasileira de Zootecnia, v.27, n.5, p.1057-1063, 1998.

MINSON, D.J. Forage in ruminant nutrition. San Diego: Academic Press, 1990. 483p.

MOOJEN, E.L.; RESTLE, J.; LUPATINI, G.C. et al. Produção animal em pastagem de milheto sob diferentes níveis de nitrogênio. Pesquisa Agropecuária Brasileira, v. 34, n. 11, p.2145-2149, 1999.

MOORE, J.E.; BRANT, M.H.; KUNKLE, W.E. et al. Effects of supplementation on voluntary forage intake, diet digestibility, and animal performance. Journal of Animal Science, v.77, Suppl. 2/J, p.122-135, 1999.

MORAES, A.; MARASCHIN, G.E. Pressões de pastejo e produção animal em milheto cv. Comum. Pesquisa Agropecuária Brasileira, v.23, n.2, p.197-205, 1988.

MOREIRA, F.B. Sistemas para crescimento e terminação de bovinos de corte: avaliação das pastagens, desempenho animal, características da carcaça e qualidade da carne. Maringá: Universidade Estadual de Maringá, 2001. 224p. Tese (Doutorado em Zootecnia) - Universidade Estadual de Maringá, 2001.

MOREIRA, F.B.; CECATO, U.; PRADO, I.N. et al. Avaliação de aveia preta cv IAPAR 61 submetida a níveis crescentes de nitrogênio em área proveniente de cultura de soja. Acta Scientiarum, v.23, n.4, p.815-821, 2001a.

MUEHLMANN, L.D.; ROCHA, M.G.; RESTLE, J. Utilização de pastagens de estação quente com bovinos desmamados precocemente. Revista Brasileira de Zootecnia, v.26, n.3, p.584-589, 1997.

NOLLER, C.H.; NASCIMENTO Jr., D.; QUEIROZ, D.S. Exigências nutricionais de animais em pastejo. In: PEIXOTO, A.M.; MOURA, J.C.; FARIA, V.P. (Eds.) Produção de bovinos a pasto. Piracicaba: Fundação de Estudos Agrários Luiz de Queiroz, 1997. p. 319-352.

NATIONAL RESEARCH COUNCIL - NRC. Nutrient requirement of beef cattle. 7.ed. Washington, D.C.: 1996. 242p.

NUSSIO, L.G.; CAMPOS, F.P.; MNZANO, R.P. Volumosos suplementares na produção de bovinos de corte em pastagens. In: REUNIÃO ANUAL DA SOCIEDADE BRASILEIRA DE ZOOTECNIA, 38., 2001, Piracicaba. Anais... Piracicaba: Sociedade Brasileira Zootecnia, 2001. p.253-275.

PEREIRA, O.G.; OBEID, J.A.; GOMIDE, J.A. et al. Produtividade e valor nutritivo de aveia (Avena sativa), milheto (Pennisetum americanum L.), e de um híbrido de Sorghum bicolor $x$ S. sudanense. Revista Brasileira de Zootecnia, v.22, n.1, p.22-30, 1993.
PRADO, I.N.; PINHEIRO, A.D.; ALCALDE, C.R. et al. Níveis de substituição do milho pela polpa de citrus peletizada sobre o desempenho e características de carcaça de bovinos mestiços confinados. Revista Brasileira de Zootecnia, v. 29, n.6, sup. 1, p.2135-2141, 2000.

RESTLE, J.; LUPATINI, G.C.; ROSO, C. et al. Eficiência e desempenho de categorias de bovinos de corte em pastagem cultivada. Revista Brasileira de Zootecnia, v.27, n.2, p.397-404, 1998.

ROSO, C.; RESTLE, J.; SOARES, A.B. et al. Produção e qualidade de forragem da mistura de gramíneas anuais de estação fria sob pastejo contínuo. Revista Brasileira de Zootecnia, v.28, n.3, p.459-467, 1999.

RYAN, W.J. Compensatory growth in cattle and sheep. Nutrition Abstracts and Reviews (Series B), v.60, n.9, p.653-664, 1990.

SECRETARIA DA AGRICULTURA E DO ABASTECIMENTO - SEAB. Manual técnico do subprograma de manejo e conservação do solo. Curitiba, PR: 1994. 372p.

SILVA, A.W.L.; MACEDO, A.F.; FRANCISCATO, C. Efeito da época de semeadura sobre o valor nutritivo de milheto, sorgo sudão e teossinto, no planalto serrano catarinense. In: REUNIÃO ANUAL DA SOCIEDADE BRASILEIRA DE ZOOTECNIA, 32., 1995. Brasília. Anais... Brasília: Sociedade Brasileira de Zootecnia, 1995. p.94-96.

SILVA, D.J. Análise de alimentos e métodos químicos e biológicos. 2.ed. Viçosa, MG: Universidade Federal de Viçosa, 1990. 165p.

TILLEY, J.M.A.; TERRY, R.A. A two-stage technique for the in vitro digestion of forage crops. Journal of British Grassland Society, v.18, p.104-111, 1963.

UNIVERSIDADE FEDERAL DE VIÇOSA - UFV. SAEG Sistema para análises estatísticas e genéticas. Versão 7.1. Viçosa: MG, 1997. 150p. (Manual do usuário).

Van SOEST, P.J. Nutritional ecology of the ruminant. 2.ed. New York: Cornell University Press, 1994. 476p.

VILARES, J.B. Exploração do ganho compensatório para produção de bovinos no trópico. In: PEIXOTO, A.M. et al. (Ed.) Nutrição de bovinos. Conceitos básicos e aplicados. Piracicaba: Fundação de Estudos Agrários Luiz de Queiroz. 2 ed. 1995. p.251-290.

WILM, H.G.; COSTELlO, O.F.; KLIPPLE, G.E. Estimating forage yield by the double sampling method. Journal of American Society Agronomy, v.36, n. 1, p.194-203, 1944.

Recebido em: 23/04/02 Aceito em: 26/12/02 